\title{
FACTORS FOR ESTABLISHING THE LIMITS OF LEGAL REGULATION
}

\author{
Ekaterina S. Zaitseva \\ Omsk Academy of the Ministry of Internal Affairs of Russia, Omsk, Russian Federation
}

\begin{abstract}
Introduction: the knowledge of the legal regulation sphere and its limits is impossible without the analysis of the factors under the influence of which it is formed. Despite the obvious significance, the factors of establishing the limits of legal regulation did not become an independent subject of research but were only indirectly affected in the context of the analysis of the legal education factors. Meanwhile, these factors are of independent importance and need additional reflection. Their identification and clarification contribute to the introduction of the concept of "smart regulation" in the law-making policy of the modern state. Purpose: to identify the factors of setting the limits of legal regulation. Methods: the methodological framework for the study was made up of the general scientific and specific scientific methods of cognition. Results: the analysis of the factors of the establishment of the legal regulation sphere and its limits with the aim of its most adequate reflection as a subject of legal regulation is a necessary condition for improving the effectiveness of the law-making policy of the modern state. Conclusions: the factors that determine the limits of legal regulation can be objective and subjective. The objective factors determine the limits of the sphere of legal regulation; as such, it is necessary to consider the properties of public relations that have a legal nature, which in turn are under the influence of the objective factors of a natural and social nature, traditionally referred to as lawforming. The main natural factors should include biological, geographical, climatic, and physiological factors. The main objective social factors are scientific and technological, axiological, economic, and psychological. The identification of the sphere of legal regulation and its consolidation as a subject of legal regulation are caused not only by the influence of the objective factors but also by the subjective ones, which should include political-legal, scientific-cognitive, and technical-legal. All these factors interact with each other and "work" in the system. Depending on the specifics of the public attitude that is in the sphere of legal regulation and is fixed as its subject, the influence of various factors will be unequal. making.

Key words: factors, limits of legal regulation, the scope of legal regulation, subject of legal regulation, law-
\end{abstract}

Citation. Zaitseva E.S. Factors for Establishing the Limits of Legal Regulation. Legal Concept = Pravovaya paradigma, 2021, vol. 20, no. 3, pp. 18-23. (in Russian). DOI: https://doi.org/10.15688/lc.jvolsu.2021.3.3

УДК 340(02)

ББК 67.0
Дата поступления статьи: 17.05.2021

Дата принятия статьи: 14.06.2021

\section{ФАКТОРЫ УСТАНОВЛЕНИЯ ПРЕДЕЛОВ ПРАВОВОГО РЕГУЛИРОВАНИЯ}

\author{
Екатерина Сергеевна Зайцева \\ Омская академия МВД России, г. Омск, Российская Федерация
} факторов, под воздействием которых она формируется. Несмотря на очевидную значимость, факторы установления пределов правового регулирования не становились самостоятельным предметом исследования, а затрагивались лишь косвенно в контексте анализа факторов правообразования. Их выявление и уточнение способствуют внедрению концепции «умного регулирования» в правотворческую политику современного государства. Цель: выявить факторы установления пределов право- 
вого регулирования. Методы: методологическую основу данного исследования составили общенаучные и частнонаучные методы познания. Результаты: анализ факторов установления сферы правового регулирования и ее пределов с целью наиболее адекватного ее отражения в качестве предмета правового регулирования является необходимым условием повышения эффективности правотворческой политики современного государства. Выводы: факторы установления пределов правового регулирования могут быть объективными и субъективными. Объективные факторы определяют пределы сферы правового регулирования, в качестве таковых следует рассматривать свойства общественных отношений, имеющих правовую природу, которые в свою очередь находятся под воздействием объективных факторов естественно-природного и социального характера, традиционно именуемых как правообразующие. К основным естественно-природным факторам следует относить биологический, географический, климатический, физиологический факторы. Основные объективные социальные факторы: научно-технологический, аксиологический, экономический и психологический. Выявление сферы правового регулирования и закрепление ее в качестве предмета правового регулирования обусловлены не только влиянием объективных факторов, но и субъективных, к числу которых следует относить политико-правовой, научно-познавательный и технико-юридический. Все они взаимодействуют между собой и «работают» в системе. В зависимости от специфики общественного отношения, находящегося в сфере правового регулирования и закрепляемого в качестве его предмета, влияние различных факторов будет неравнозначным.

Ключевые слова: факторы, пределы правового регулирования, сфера правового регулирования, предмет правового регулирования, правотворчество.

Цитирование. Зайцева Е. С. Факторы установления пределов правового регулирования // Legal Concept = Правовая парадигма. - 2021. - Т. 20, № 3. - C. 18-23. - DOI: https://doi.org/10.15688/lc.jvolsu.2021.3.3

\section{Введение}

Познание сферы правового регулирования как совокупности общественных отношений, сопровождающих их жизненных фактов и обстоятельств, которые объективно должны быть подвергнуты правовой регламентации, предполагает анализ факторов, под воздействием которых могут изменяться ее пределы. В 80-е гг. XX в. проблематика факторов правообразования находилась в фокусе внимания исследователей. Именно в этот период они были выявлены, обоснованы и классифицированы. Несмотря на очевидную связь факторов правообразования и факторов установления пределов правового регулирования, последние представляют самостоятельный исследовательский интерес и нуждаются в дополнительном осмыслении с учетом накопленного опыта анализа правообразовательных факторов в целом. Выявление и уточнение факторов установления пределов правового регулирования способствуют внедрению концепции «умного регулирования» [1, с. 14-20] в практику современного правотворчества, позволяя учитывать естественно-природные и социальные механизмы их воздействия на общественные отношения.

\section{Общественные отношения, имеющие правовую природу, как объективный фактор установления пределов сферы правового регулирования}

Пределы сферы правового регулирования обусловлены общественными отношениями, имеющими правовую природу. Определение правовой природы указанных отношений связано с наличием свойств-критериев, среди которых следует выделять те, что являются общими для установления границы между любыми социальными регуляторами и сферами человеческого бытия, регулируемыми законами природы, к их числу мы относим волевой характер общественных отношений и возможность выбора варианта поведения. Свойства общественных отношений, имеющих непосредственно правовую природу - это возможность осуществления социального контроля, направленность общественных отношений на удовлетворение типичных, социально значимых, конфликтных интересов и эквивалентный характер [2, с. 82-109].

Указанные общественные отношения, в том числе и формирование обозначенных свойств-критериев, выступая в качестве объективного фактора, определяющего пре- 
делы сферы правового регулирования, в то же время находятся в прямой зависимости от тех объективных факторов, которые традиционно в юридической литературе рассматриваются как правообразующие. Преломляясь в общественных отношениях, они оказывают влияние на свойства-критерии, обусловливающие их правовую природу, и выступают уже в качестве объективных факторов формирования указанных общественных отношений. Из всех указанных свойств наиболее подверженным влиянию разного рода объективных правообразующих факторов является направленность общественных отношений на удовлетворение типичных, социально значимых конфликтных интересов.

\section{Естественно-природные объективные факторы}

Основное внимание исследователей сконцентрировано на анализе объективных социальных правообразующих факторов. Отдельные естественные факторы хоть и обозначаются, но зачастую рассматриваются в контексте анализа объективных социальных факторов. Исключение составляет монографическое исследование А. Нашиц [3], в котором естественным факторам уделено существенное внимание. Между тем естественные факторы имеют как свою специфику, так и самостоятельное значение. К числу основных факторов естественно-природного характера, оказывающих влияние на общественные отношения, имеющие правовую природу, следует относить прежде всего биологический, географический, климатический, физиологический факторы. Так, географический фактор оказывает существенное влияние на типичный, социально значимый конфликтный интерес, который во многом определяется земельными, атмосферными, водными богатствами и ресурсами, эксплуатируемыми человеком. Особенности географической среды различных государств накладывают отпечаток на сферу и пределы правового регулирования, определяя различные правовые режимы эксплуатации земель, лесов, рек и т. д. Естественно-природные факторы характеризуются тем, что все явления и процессы, их составляющие, протекают по собственным законам и абсолютно не зависят от сознания и воли людей. Естественно-природные факторы менее динамичны, чем социальные, поэтому в стабильной обстановке их влияние не так ощутимо, как, например, в чрезвычайных условиях.

Ярким примером проявления биологического фактора, показавшим его значение, является пандемия COVID-19 как чрезвычайное обстоятельство мирового масштаба, изменившее привычные условия жизнедеятельности людей и оказавшее существенное влияние на правовое регулирование и его пределы. Под воздействием пандемии произошла существенная трансформация типичных, социально значимых конфликтных интересов. Многие интересы, не имеющие социального значения и потенциальной конфликтности в обычной ситуации, получают эти признаки в настоящее время, что обусловливает расширение сферы правового регулирования и закрепления ее в качестве предмета. Так, например, если в обычных условиях передвижение человека как свобода в соответствии со ст. 27 Конституции РФ предполагает, что время, место, конечный пункт движения находятся вне сферы и предмета правового регулирования, то в период пандемии такие, по своей природе личные, частные аспекты жизнедеятельности, находящиеся в зоне саморегуляции, приобрели потенциальную конфликтность и социальную значимость, войдя в сферу правового регулирования и получив отражение в качестве его предмета. В частности, в соответствии с подпунктом «в» пункта 2 Указа Президента РФ от 02.04.2020 № 239 [9] нормативными правовыми актами субъектов РФ в регионах был установлен особый порядок передвижения граждан и транспортных средств.

Таким образом, естественно-природные факторы установления пределов правового регулирования нуждаются в дальнейшем осмыслении, в то же время сила воздействия естественных факторов может быть понята только с учетом взаимосвязи и взаимозависимости с факторами социальными [3, с. 41].

\section{Социальные объективные факторы}

Важнейшими объективными факторами социального характера являются экономический, научно-технологический, аксиологический, 
психологический. Все они объективны постольку, поскольку являются внешними по отношению к сфере правового регулирования, но в то же время и субъективны, поскольку формируются в результате социального взаимодействия людей. Так, например, объективные экономические законы претворяются в реальные отношения через активную деятельность людей, вследствие чего их проявления в конкретных исторических условиях будут различны [4, с. 62].

При анализе правообразующих социальных факторов особое внимание уделяется экономическому фактору, его отмечают основным [8, с. 138]. Не отрицая его значения, хочется отметить, что на сегодняшний день на сферу правового регулирования и его пределы существенное влияние оказывает научно-технологический фактор. Стоит сказать, что традиционно научный фактор рассматривается как один из обеспечивающих факторов, который связан с раскрытием путей и форм обеспечения научной обоснованности законов [6, с. 79; 8, с. 145]. В этом контексте научный фактор связан с обеспечивающей ролью юридической науки по отношению к правотворческой деятельности. Это положение не вызывает возражений, но помимо обеспечительной роли юридической науки нельзя не заметить, что научно-технологический прогресс как глобальный процесс оказывает существенное воздействие и на правообразование в целом, и на сферу и пределы правового регулирования в частности. Если в начале 80$\mathrm{x}$ гг. констатировалось расширение сферы правового регулирования под влиянием использования автоматических систем и возникающих в связи с этим общественных отношений, связанных с их эксплуатацией и т. п. [4, c. 38], то в XXI в. влияние научно-технологического фактора проявляется в процессах цифровизации, под воздействием которой происходит изменение как сферы, так и предмета правового регулирования.

Не менее значимым является аксиологический фактор, предполагающий, что сфера правового регулирования ограничена правовыми ценностями как сравнительно устойчивыми категориями, исходящими из правовых традиций общества и государства и определяющими векторы и стратегии правово- го развития [7, с. 24]. Законодателю приходится с этим считаться, поскольку явное несоответствие создаваемых правовых моделей и институтов основным ценностным установкам заведомо снижает их эффективность. Более того, многие ценности настолько укоренились в сознании современного общества, что государство даже при желании вряд ли может через них переступить. Например, сложно представить, что современный законодатель может проигнорировать ценность чести и достоинства человека и закрепить возможность применения пыток, ушедших из сферы правового регулирования еще в XIX веке.

Воздействие экономического фактора на сферу правового регулирования определяется прежде всего тем, что объективные экономические законы очерчивают сферу правового регулирования и любое произвольное вмешательство в эту сферу влечет за собой негативные последствия. В частности, влияя на формирование типичного, социально значимого конфликтного интереса, экономический закон спроса и предложения приводит к тому, что возникающие в связи с его удовлетворением общественные отношения, не находя адекватного отражения в предмете правового регулирования, автоматически не исключаются из сферы правового регулирования, а уходят в область теневого права.

Психологический фактор предполагает наличие закономерностей функционирования человеческой психики, ее способности сознательно воспринимать и усваивать правила поведения и строить в соответствии с ними свои поступки и взаимоотношения. Абсолютно справедливо отмечается, что «способность правовых норм к воздействию на личность не может быть шире способности ее к восприятию такого воздействия на психологическом уровне. Несоответствие же этих способностей является одним из источников противоречий между правовым регулированием и социальной действительностью» [5, с. 45].

Итак, сфера правового регулирования и ее пределы обусловлены общественными отношениями, обладающими целым рядом свойств-критериев, определяющих их правовую природу. Выступая в качестве объективного фактора установления пределов сферы правового регулирования, указанные отноше- 
ния находятся под воздействием целого ряда объективных правообразующих факторов.

\section{Субъективные факторы установления предмета правового регулирования}

К числу основных факторов, имеющих субъективный характер, можно отнести: политико-правовой, научно-познавательный и технико-юридический. Политико-правовой фактор является определяющим субъективным фактором, посредством которого «переплавляются〉 все объективные явления и процессы, находящие отражение в выше обозначенных объективных факторах. Так, например, наличие правовых ценностей, определяющих границы правового регулирования, предполагает возможность установления их иерарахии с целью определения того, при помощи каких средств можно способствовать либо препятствовать развитию тех или иных отношений, какова должна быть интенсивность предоставляемой им правовой защиты или борьбы против них с помощью правовых норм [3, c. 88]. А это уже зависит от политической воли законодателя.

Научно-познавательный фактор предполагает, что только в результате научного познания можно среди всего многообразия общественных отношений отфильтровать те, которые имеют правовую природу и характеризуются необходимыми свойствами-критериями. В этой связи представляется необходимым не только осуществлять дальнейшую научную разработку критериев установления пределов сферы правового регулирования, но также и обратиться к проблеме индикаторов, позволяющих эти критерии определять. Другое дело, что степень использования законодателем достижений науки зависит от позиции самого законодателя. А для этого требуется и желание, и постоянные усилия [3, с. 84].

Технико-юридический фактор предполагает использование технологий, методов и средств, способствующих установлению пределов сферы правового регулирования. К их числу можно отнести юридическое прогнозирование, правовой мониторинг, оценку регулирующего воздействия, правовой эксперимент и многие другие. И здесь важно не только наличие соответствующего инструментария, но и желание со стороны властных субъектов его использования. В отечественной науке, занимавшейся разработкой этих вопросов, акцентировалось внимание на рекомендательном характере использования указанных инструментов, в то время как в западных концепциях регулирования постулируется их обязательное значение [1, с. 18]. В то же время обязательность использования любой технологии, метода или средства также не является панацеей, поскольку может быть нивелирована формальным отношением в процессе ее реализации.

\section{Выводы}

Таким образом, факторы установления пределов правового регулирования могут быть объективными и субъективными. Объективные факторы определяют границы сферы правового регулирования, в качестве таковых следует рассматривать свойства общественных отношений, имеющих правовую природу. Среди них особое место занимает направленность общественных отношений на удовлетворение типичного, социально значимого конфликтного интереса. В свою очередь, общественные отношения, имеющие правовую природу, находятся под воздействием целого ряда объективных факторов естественно-природного и социального характера, которые традиционно именуют как правообразующие. К основным естественно-природным факторам следует относить биологический, географический, климатический, физиологический. Основные объективные социальные факторы - это научно-технологический, аксиологический, экономический и психологический. Процесс установления пределов предмета правового регулирования обусловлен влиянием не только объективных факторов, но и субъективных, к числу которых следует относить политико-правовой, научно-познавательный и технико-юридический. Все указанные факторы взаимодействуют между собой и «работают» в системе, их разграничение осуществляется прежде всего в познавательных целях. В зависимости от специфики общественного отношения, находящегося в сфере правового регулирования и закрепляемого в качестве его предмета, влияние различных факторов будет неравнозначным. 


\section{СПИСОК ЛИТЕРАТУРЫ}

1. Давыдова, М. Л. «Умное регулирование» как основа совершенствования современного правотворчества / М. Л. Давыдова // Журнал российского права. - 2020. - № 11. - С. 14-20.

2. Зайцева, Е. С. Пределы правового регулирования (общетеоретический аспект) / Е. С. Зайцева. Омск : Омская академия МВД России, 2020. - 153 с.

3. Нашиц, А. Правотворчество / А. Нашиц. М. : Прогресс, 1974. - 256 с.

4. Научные основы советского правотворчества / под ред. Р. О. Халфиной. - М. : Наука, 1981. - 317 с.

5. Новик, Ю. И. Психологические проблемы правового регулирования / Ю. И. Новик. - Минск : Университетское, 1989. - 135 с.

6. Поленина, С. В. Законотворчество в Российской Федерации / С. В. Поленина. - М. : ИГПАН, 1996. $-145 \mathrm{c}$.

7. Правовые ценности в свете новых парадигм развития современной цивилизации : сб. науч. тр. / под общ. ред. Д. А. Пашенцева. - М. : Инфра-М, 2020. $-430 \mathrm{c}$.

8. Трофимов, В. В. Правообразование в современном обществе: теоретико-методологический аспект / под ред. Н. А. Придворова. - Саратов : Изд-во ГОУ ВПО, 2009. - 308 с.

9. Указ Президента РФ от 02.04.2020 № 239 «О мерах по обеспечению санитарно-эпидемиологического благополучия населения на территории Российской Федерации в связи с распространением новой коронавирусной инфекции (COVID-19)». Электрон. текстовые дан. - Режим доступа: http:// publication.pravo.gov.ru0001202004020025 (дата обращения: 15.05.2021). - Загл. с экрана.

\section{REFERENCES}

1. Davydova M.L. «Umnoye regulirovaniye» kak osnova sovershenstvovaniya sovremennogo pravotvorchestva [«Smart Regulation» As the Basis for Improving Modern Lawmaking]. Zhurnal rossiyskogo prava [Journal of Russian Law], 2020, no. 11, pp. 14-20.

2. Zaytseva E.S. Predely pravovogo regulirovaniya (obshcheteoreticheskiy aspect) [Limits of Legal Regulation (General Theoretical Aspect)]. Omsk, 2020. 153 p.

3. Nashits A. Pravotvorchestvo [Lawmaking]. Moscow, 1974. 256 p.

4. Nauchnyye osnovy sovetskogo pravotvorchestva [Scientific Foundations of Soviet Law-making]. Moscow, 1981. 317 p.

5. Novik Yu.I. Psikhologicheskiye problemy pravovogo regulirovaniya [Psychological Problems of Legal Regulation]. Moscow, 1989. 135 p.

6. Polenina S.V. Zakonotvorchestvo v Rossiyskoy Federatsii [Lawmaking in the Russian Federation]. Moscow, 1996. 145 p.

7. Pravovyye tsennosti $v$ svete novykh paradigm razvitiya sovremennoy tsivilizatsii: $s$. nauch. $t$. [Legal Values in the Light of New Paradigms of the Development of Modern Civilization: Collection of Scientific Papers]. Moscow, 2020. 430 p.

8. Trofimov V.V. Pravoobrazovaniye $v$ sovremennom obshchestve: teoretiko-metodologicheskiy aspekt [Legal Education in Modern Society: Theoretical and Methodological Aspect]. Pridvorov N.A., ed. Saratov, 2009.308p.

9. Ukaz Prezidenta RF ot 02.04.2020 № 239 «O merakh po obespecheniyu sanitarno-epidemiologicheskogo blagopoluchiya naseleniya na territorii Rossiyskoy Federatsii v svyazi s rasprostraneniyem novoy koronavirusnoy infektsii (COVID-19)» [Decree of the President of the Russian Federation of 02.04.2020 No. 239 "On Measures to Ensure the Sanitary and Epidemiological Well-Being of the Population on the Territory of the Russian Federation in Connection with the Spread of a New Coronavirus Infection (COVID-19)"']. URL: http:// publication.pravo.gov.ru 0001202004020025 (accessed 15 May2021).

\section{Information About the Author}

Ekaterina S. Zaitseva, Candidate of Sciences (History), Associate Professor, Department of Theory and History of Law and State, Omsk Academy of the Ministry of Internal Affairs of Russia, Prosp. Komarova, 7 , 644092 Omsk, Russian Federation, zay_tseva@mail.ru, https://orcid.org/0000-0003-0688-2967

\section{Информация об авторе}

Екатерина Сергеевна Зайцева, кандидат исторических наук, доцент кафедры теории и истории права и государства, Омская академия МВД России, просп. Комарова, 7, 644092 г. Омск, Российская Федерация, zay_tseva@mail.ru, https://orcid.org/0000-0003-0688-2967 